\title{
Theory comparison and choice in chemistry, 1766-1791
}

\author{
Geoffrey Blumenthal ${ }^{1} \cdot$ James Ladyman $^{1}$
}

Published online: 23 October 2017

(C) The Author(s) 2017. This article is an open access publication

\begin{abstract}
This is the second of a pair of papers, of which the first showed how each of the main late phlogistic theories effectively reached impasses due to internal problems or included features which made them unacceptable even to other phlogistians. This paper deals with theory comparison and theory change. It gives an unprecedentedly detailed comparison between the available theories in 1790-1791, and shows that this was overwhelmingly in favour of the new chemistry. This time period correlates well with many chemists changing to the new theory. There was a plurality of views held by individuals and there was freedom of individual choice concerning theories, yet there was also a widespread and rational change to the new chemistry.
\end{abstract}

Keywords Theory comparison - Theory choice · Phlogiston · Lavoisier · Cavendish · Priestley · Kirwan · Scheele $\cdot$ Gren · Macquer

\section{Introduction}

This is the second of two papers. The first dealt with the development of problems in the later phlogistic theories, and the present paper deals with theory comparisons and theory choices for the same period. This paper sets out, for the first time in the literature, comparisons concerning a very wide range of aspects of several phlogistic theories, with separate sections on specific topics or collections of topics that were perceived by contemporaries as being important for theory comparison. This is a guide to the material that could potentially have been taken into account by individuals, provided that they had sufficient information and time, and that they were sufficiently free from preconception.

Geoffrey Blumenthal

gb0859@bristol.ac.uk

1 Department of Philosophy, University of Bristol, Cotham House, Cotham Hill, Bristol BS6 6JL, UK 
The information in this paper supports the following general points concerning theory comparisons at this period:

Firstly, the choices made by individuals differed according to a large number of variables: individuals had differing access to information; they brought differing preconceptions to bear on the information that they had; they were subject to differing degrees of pressure from others or from social groups; there were differences in the extent to which they could or did ignore information that was inconvenient to them; and they achieved different understanding of the information that they possessed; all this resulted in the remarkable differences between the published views that are summarised in the comparisons in this paper. Secondly and partly as a result, there was no large-scale change in the theories held by individuals until it was possible to make a wide range of comparisons which showed that the overall advantage was with the new chemistry. Thirdly, by 1790-1791, a dispassionate and detailed comparison of a wide range of aspects of the theories was overwhelmingly in favour of the new chemistry. Analysis relative to earlier dates of the details that are given in the comparison sections would show that overall comparison would have been less clear at earlier dates; the turning point was in 1785 and comparisons were increasingly clear from 1787 onwards. Fourthly, the period from 1785 to 1791 correlates well with an increasing number of chemists changing to the new theory. Fifthly, there was no stage at which "the profession agreed" or "the other side gave up the struggle". Sixthly, accordingly in overall terms there was freedom of individual choice concerning theories and a plurality of individual positions, and yet there was also a very widespread and rational change to the use and development of the new chemistry.

It is not possible to deal in this paper with all the matters that are relevant to the history of chemistry in this period. There are additional ways in which the theories could be compared, including in terms of simple substances and compounds which will be considered in a separate paper. There are many philosophical, social and contextual issues which are important and relevant but which cannot be discussed within the scope of this paper. Many issues which are briefly mentioned in this paper potentially deserve more detailed treatments. Concerning the secondary literature, the points made in Blumenthal and Ladyman (2017) remain relevant, but otherwise the secondary literature will not be explored further in this paper.

All the remaining sections in this paper give comparisons between the main theories at 1790-1791. The next section clarifies the theories which are being compared. Theory comparisons are given concerning the gas that Lavoisier called "oxygen"; the natures of several other gases; calcination; the natures of water and of acids. Theory comparisons are then given concerning the natures of heat, change of state, expansion, fluidity, combustion, and phlogiston. Theory comparisons are produced in terms of general epistemic concepts that were in use at the time - simplicity, consistency, scope, the potential for further discoveries, testability, the solution of problems, and overall strategies. Theory comparisons are given concerning "losses" by a theory of parts of a former theory. Finally some general points are made concerning theory comparison. 


\section{Theory comparisons in 1790-1791}

\section{The theories that are being compared}

In both the primary and secondary literature on theory comparison for this period, one tactic has been to be imprecise or inaccurate about what theories are actually being compared. For example, Macquer argued that he was defending Stahl's theory of phlogiston, but actually created his (1778, v. 3, pp. 122 and 132) own hybrid in which phlogiston was matter of light. Cavendish (1784a, p. 152) argued that he was defending the "common received principle of phlogiston" but really put forward his own version in which phlogiston was present in calces as well as metals.

If the position is taken that there was $a$ phlogiston theory or a system of phlogistic theories, then comparison with the Lavoisian position needs to take into account the whole of that phlogiston theory or system of theories, or at least all of the main theories in a system of theories. Alternatively, if one phlogistic theory is taken for comparison purposes, such as Cavendish's (1784a) theory, then the whole of that theory and only the whole of that theory needs to be taken into account, not just the explanation for the composition of water. Few of the actual published comparisons have followed such principles, but the information given in this paper enables such alternative comparisons. Cavendish's theory is treated as still current in public terms in 1790, since he did not officially renounce phlogiston, and Scheele's 1785 theory is treated as still current because it was still considered as needing to be criticised.

\section{Theory comparisons concerning the nature of the type of air that Lavoisier called "oxygen"}

The available theory by Cavendish (1784a, p. 137) was that this air was dephlogisticated water. However, he had subsequently publicly stated that this theory was not fully consistent with his other explanation concerning this air, which was $(1785$, p. 380$)$ that the removal of this air from a substance was equivalent to the addition of phlogiston to that substance. It was the latter explanation which was assessed by some later historians as indicating why a theory of phlogiston could be regarded as having had a significant degree of apparent success prior to the discovery of this air. It was also potentially practicable at the time to analyse Cavendish's theory and to realise not only that Cavendish's views were more inconsistent than he had realised, but also that the discovery of oxygen effectively made a continuing theory of phlogiston-as-negative-oxygen impracticable, as has been outlined in the first paper (Blumenthal and Ladyman 2017, pp. 260-261). Cavendish's theory for this air had been immediately challenged by Kirwan (1784a, b). By contrast, Kirwan $(1789$, p. 4) himself had argued that Lavoisier had "proved... that pure air... contained more fire than any other air".

By 1791, Priestley's published work included a succession of problematic and sometimes wildly different hypotheses about the constitution of this air, ${ }^{1}$ of which several examples have been previously listed (Blumenthal and Ladyman 2017, pp. 252-253, 265, 267). In addition, he (1786, p. 290) thought that this air was a compound of nitric acid and

\footnotetext{
1 Partington (1962, pp. 262-3), concluded that "it is not easy to extract from his conflicting statements Priestley's considered views (if he had any) on the nature of oxygen and nitrogen". McEvoy (1978, p. 168), notes that during 1775-81 "Priestley's views on the composition of dephlogisticated air were continually changing".
} 
heat, while he also (1786, p. 402) thought that it was a simple substance. His (1790c, p. 535) view was that "water seems to constitute about nine parts in ten of dephlogisticated air". It was potentially possible by analysing the published information to identify that Priestley's "dephlogisticated air" was empirically incorrect relative to the experiment in which he had first produced that air (Blumenthal and Ladyman 2017, p. 252) and tied his name, which became used by many phlogistians, to a phlogistic theory.

Scheele had produced two theories concerning the constitution of this air, both of which were untestable. His (1931, p. 162) first view was that this "fire air" consisted of the aerial acid $^{2}$ and phlogiston, while his (1931, p. 286) late view was that fire air consisted of the "saline principle", a small quantity of phlogiston, and some water. Gren (1790, p. 457) said that dephlogisticated air was water plus matter of heat, but this theory was testable and could have been shown at the time to be untenable.

By contrast, Lavoisier had undertaken experiments on the basis of which he produced a series of consistent theories about this gas, which were testable by repeating the experiments. He distinguished this air from "fixed air" (1775/8, pp. 125-127) and from the air left over after calcination in closed conditions $(1777 \mathrm{~b}, \mathrm{p} .175)$ on the basis of lists of their properties. He had shown on the basis of a series of experiments that the weight gain of metals during calcination in closed conditions was approximately equal to the weight of air absorbed by these metals (1774, p. 620). He (1777e, p. 226) had identified that substances burned "only in a very small number of types of air". He (1776, 1777a, c, 1778, p. 249) had demonstrated that several then-known acids contained pure air; and (1778, p. 251) noted that in cases in which a substance could form more than one acid with different proportions of pure air, the acid with the greater concentration of pure air was more acidic. On all this basis he had theorised that pure air (oxygen) was a "simple [undecompounded] substance" which combined with other simple substances to form compounds. All this was central to the compositional theory that was available in the Nomenclature (Guyton et al. 1787) and in a refined version in the Traité (Lavoisier 1789).

By 1791, three of Lavoisier's hypotheses had been shown to be over-generalisations or possibly to be incorrect due to available anomalous evidence. The hypothesis (1777e, p. 226) that substances burned "only in a single type of air" (pure air), was now clearly an over-generalisation due to the work of Westrumb (1790), who showed comprehensively that a wide range of substances burned in dephlogisticated marine acid. ${ }^{3}$ The hypothesis (1777e, p. 226) that all burned substances changed into acids due to the addition of the substance that increased their weight had already been amended due to the non-acidity of calces and water. The hypothesis (1778, p. 249) that all acids contained oxygen, was now known to be subject to at least one almost certain anomaly, prussic acid. These points will be further explained in the section on acids below. There were also objections that his name for the air, "oxygen", was etymologically questionable and was tied to his theory.

In overall terms, anyone who had access to a reasonably full range of information on these subjects could see that there was no general "phlogiston theory" concerning this air, but there were numerous mutually-incompatible, unsuccessful and experimentally untestable or untested phlogistic theories, none of which was accepted by main participants other than their authors. It was also potentially understandable that the theory of phlogiston-as-negative-oxygen had several inescapable problems, although no phlogistian had publicly admitted this. By contrast, the new chemistry's theory for this gas was based on experiments and was largely successful, even if some of Lavoisier's initial generalisations

\footnotetext{
2 "Fixed air", now $\mathrm{CO}_{2}$.

3 This was Scheele's name for the substance, now known as chlorine.
} 
about the gas had been abandoned or were running into anomalies. This overall comparison explains why it was rational to change to the new chemistry at this time.

\section{Theory comparisons concerning the natures of several other types of air}

On inflammable air, Cavendish (1766, p. 145) had hypothesised that phlogiston formed inflammable air. His latest published view (1784a, p. 137) was that this still might be the case, but he now preferred the view that inflammable air from metals was water plus phlogiston. Both of these views could potentially be seen at the time as having several problems (Blumenthal and Ladyman 2017, pp. 7-8 and 19-20). Cavendish's (1784a, p. 137) view that phlogiston might still be inflammable air was not consistent with his (1785, p. 380) theory that the addition of phlogiston was equivalent to deprivation of "dephlogisticated air". Also, his new view that inflammable air was water plus phlogiston was not compatible with Stahl's and Macquer's (e.g. 1766, v. 1, p. 20; v. 2, p. 205) views that phlogiston had little or no tendency to unite with water or the acqueous principle.

Contrary to Cavendish's views, Kirwan's (1789, p. 168) view was that inflammable air in solid form was phlogiston and $(1789$, p. 284) that water was in no way essential to inflammable air. Scheele (1931, p. 334) stated that inflammable air was formed by heat and phlogiston, but he (1931, p. 287) also proposed that inflammable air consisted of the saline principle and phlogiston. Scheele (1931, p. 287) argued that water was the chief cause of the weight of air and argued (effectively contrary to Cavendish's view) that the lack of content of water was the cause of the lightness of inflammable air. Priestley (1786, p. 406) had stated that inflammable air "seems now to consist of water and inflammable air, which seems extraordinary", but then (1788a, p. 152) agreed with Cavendish that inflammable air contained water and phlogiston. A section in Priestley's (1790a) first compilation volume was entitled "experiments which prove that water is a necessary ingredient in inflammable air", but it was readily understandable by an informed reader that the described experiments did not do so. Gren's (1790, p. 457) theory was that inflammable air from metals was matter of heat plus water plus phlogiston plus vitriolic or muriatic acid.

Cavendish's (1784a, p. 136) theory concerning the gas that Priestley had called "phlogisticated air" was that it was nitrous acid united to phlogiston, and (1784a, p. 141) that it was a separate substance from "dephlogisticated air" and that the two were distinguished by more than content of phlogiston. Priestley's published views included (1775b, p. 392) that this air differed from common air and dephlogisticated air only in terms of different content of phlogiston, (1786, pp. 404-405) that it was phlogiston plus the dephlogisticated nitrous vapour, and (1790c, pp. 537-538) that "we know but little of the nature of phlogisticated air, but that it contains phlogiston, seems to be evident from its assisting to form nitrous acid with dephlogisticated air... phlogisticated air contains all the phlogiston in the nitrous air". His statement that "we know but little" of its nature was potentially arresting in that he had done more experimental work on this gas and on various types of nitrous air than anybody else during the period. Gren's (1790, p. 457) view was that phlogisticated air was matter of heat plus water plus phlogiston.

Concerning common air, Cavendish (1784a, p. 141) was in agreement with Lavoisier and Scheele that common air was a mixture of dephlogisticated and phlogisticated air which were separate substances, with a small proportion of fixed air. Priestley's current published views on common air included (1790c, pp. 378-380) that it was dephlogisticated air and phlogisticated air, or that it was phlogisticated (1790c, p. 385) or that it was an element and became phlogisticated (1790b, p. 188). 
Concerning fixed air, Priestley's collection of published views included (1772, p. 162) that fixed air and phlogiston produced common air; (1789, pp. 11-12) that fixed air was formed from phlogiston and the principle of acidity; (1790a, pp. 145 and 159) that fixed air was composed of dephlogisticated air and phlogiston, but also that water was an essential ingredient of fixed air (1790a, p. 129), and also that "fixed air seems to consist of about one half water and the other half phlogiston, and dephlogisticated air in the proportion of one fourth of the former, to three fourths of the latter" (1790c, p. 536). He (1790a, p. 133) also theorised that "nitrous air and fixed air, consist of the same elements differently combined". Kirwan's (1789, p. 43) theory was that fixed air could be formed by inflammable air and dephlogisticated air at low heat, and this proved to be the Achilles' heel of his whole theory. ${ }^{4}$ Gren's (1790, p. 457) view was that fixed air was acidum sui generis plus heat plus water.

In comparison, in Lavoisier's theory (1790, p. 175), azote (nitrogen) and hydrogen were "simple substances", 'fixed air' was carbonic acid-a combination of charcoal and oxygen, and common air was a mixture of azote and oxygen. These views fitted into the largescale structure of chemical composition that was given in the Traité. The Lavoisians' theory was that Cavendish's (1785) experiments demonstrated that nitrous acid contained both dephlogisticated air and phlogisticated air (Guyton 1786, p. 633). This overall comparison shows clearly why it was rational to change to the new chemistry in 1790-1791.

\section{Theory comparisons concerning calcination}

Almost all the views on calcination that were current in 1790-1791 were departures from Stahl's theory. He (1703; 1771, pp. 13-14; Juncker 1757, v. 1, p. 66) held that the addition of phlogiston to calces formed metals, that air could not be combined in solids (e.g. 1731; Juncker 1757, v. 1, pp. 124-5), and that the phlogiston that was disengaged during calcination was not collectable, so that the presence of phlogiston could only be inferred from its transference from one combination to another (1766, pp. 56-57; Juncker 1757, p. 151). Although a known anomaly with this view was that substances gained in weight during calcination, the result of Guyton's (1772) demonstration that this was a general phenomenon together with his unsatisfactory attempt to provide an explanation, was that "the work which had been done to try to perfect the system of phlogiston had insensibly prepared its ruin", as Guyton had stated (1786, pp. 626-627).

Lavoisier (1774) had shown experimentally that as a general phenomenon, calcination involved the absorption of air, that this fully accounted for the gain in weight during calcination, and (1775/8, pp. 125-127) that it was very probable that calces always contained pure air (oxygen). By providing evidence for what was transferred from one combination to another in calcination, this removed the key available evidence that had previously been held to support a theory of phlogiston.

The earliest of the available revised phlogistic theories that fully accepted that air was absorbed in calcination was by Macquer (1778, v. 1, pp. 348-353). In Macquer's (1778, v. 3 , pp. 122 and 132) new theory, phlogiston was retained in the new guise of matter of light. Among the particular problems of this view was the evidence that focussing light on substances affected them in different ways than those produced by burning them with charcoal. Macquer's view had been comprehensively criticised by Lavoisier (1785).

\footnotetext{
4 As is shown by Kirwan's letters of 1791 renouncing phlogiston. These are given in Lavoisier (1997, p. 227); and Kirwan (1791, p. 425), or Grison et al. (1994, pp. 198-9).
} 
In the main genre of the available revised phlogistic theories, which was initiated by Cavendish, phlogiston was retained in calces and combined with incoming dephlogisticated air to form something else, which in the case of his (1784a, p. 144) theory was water. This theory was inconsistent with his (1784a, p. 136) contemporary theory of acids (Blumenthal and Ladyman 2017). Cavendish's theory about calces was immediately criticised by Kirwan (1784a, b), who proposed an alternative revised theory in which dephlogisticated air and phlogiston could form fixed air and did so in calces. Priestley had published two theories each of which supported one of these options for what was contained in calces, but for reasons which differed not only from those of Cavendish and Kirwan but also from each other. Priestley's (1788a, p. 155) view was that red precipitate of mercury contained water, but this was on the basis of heating it in inflammable air and finding water, yet his (1790c, p. 546) view was that heating red precipitate in inflammable air "always" formed fixed air. Westrumb (1787, p. 135, 1788a, p. 290) apparently followed Cavendish's view that during calcination, pure air was absorbed and combined with the phlogiston in the metal to form water in the calx, so that the calx consisted of an earth and water (1788b, p. 361). However, during the experiments and controversies of 1791-1793 Westrumb expected that it was water that would be produced on reduction.

The available theory in 1790-1791 that maintained Stahl's basic view on calcination was by Gren. This involved the denial that air was embodied or fixed (1787, p. 212, 1788c, p. 344), which did not properly take into account Lavoisier's (1774) Opuscules, Bayen's (1774, 1775) experiments, Priestley's (1774, p. 193, 1775a, pp. 34-35) work on the production of air during reduction, and the fact that experimenters in England and France were now routinely obtaining pure air from calces for experimental purposes.

The removal of the only supposed indirect evidence for the existence of phlogiston had not deterred the formation of several further phlogistic theories. It is interesting that none of the participating phlogistians foresaw that it would prove to be impracticable to find a viable revised phlogistic theory of calcination, and several of them spent a large amount of effort over years in attempting to do so. Yet by 1790-1791 it could be seen by a participant with a full range of information that such theories were inevitably partly non-Stahlian, that it was turning out to be impracticable to find any experimental evidence that confirmed the presence of anything like the original phlogiston in substances in one of the recentlyproposed revised forms, and that no theory of this type succeeded in being acceptable even to other phlogistians, other than in the short-term. For any participant who understood this, it was rational to change to the new chemistry.

\section{Theory comparisons concerning the nature of water}

The central available theory of water in 1790-1791 was Lavoisier's theory that pure air and inflammable air were each "simple substances", and (1783) that they combined to form the water that resulted in the experiment in which the two airs were exploded together. This was supported in that the weights of the component gases approximately equalled that of the resulting water in the experiment. This had now been confirmed by a very detailed experiment. $^{5}$

As was the case with calcination, the earliest of the main genre of late phlogistic theories on the topic was by Cavendish. His (1784a, p. 137) theory that in this experiment the water was already present in the initial airs was not supported by any direct experimental evidence. The large number of problems with this view (Blumenthal and Ladyman

${ }^{5}$ Lavoisier et al. (1790), Fourcroy et al. (1791), Séguin (1791). 
2017, pp. 259-262) also included, as already discussed, that Stahl and Macquer had stated that water was inimical to phlogiston. The theory by Scheele (1931, p. 288) was partly similar, and involved that when dephlogisticated air and inflammable air were exploded together, the saline principle of the dephlogisticated air combined with the phlogiston of the inflammable air to form heat and light which escaped through the glass of the container, leaving behind the water that was present in the dephlogisticated air. This implied the loss of weight in the experiment, which was reasonably criticised as being experimentally inaccurate (Leonhardi 1790, v. 6, p. 604). Priestley's theory echoed Cavendish's view that the water produced in the experiment on the combination of dephlogisticated air and inflammable air had already been present as a constituent of each of the gases. Yet Priestley's theory differed from Cavendish's concerning the constitution of dephlogisticated air, and concerning the products of the experiment. Priestley argued that phlogiston and the "principle of acidity" formed the nitrous acid in the experiment, and also formed residual fixed air, or phlogisticated air when these were residually present in the experiment. The large number of problems with this view have been very briefly summarised (Blumenthal and Ladyman 2017, pp. 265-267). The theory by Kirwan (1784a) differed from Cavendish's (1784a) view by accepting that inflammable air (which he thought was phlogiston) and dephlogisticated air could combine to form water, and (1789, p. 284) by reasonably arguing that water was not a constituent of inflammable air.

It is again interesting that the work on the composition of water, and the lack of evidence for the pre-existence of water in gases, did not deter the production of several late phlogistic theories about water. Yet by 1790-1791 it was turning out to be impracticable to find any experimental evidence that confirmed any of these theories, and the appearance of the Nomenclature in 1787 and the Traité in 1789 provided a sidelight on the lack of potential for the late phlogistic theories of water to become viably competing general theories. All this correlated with theory change by an increasing number of participants.

\section{Theory comparisons concerning the natures of acids}

Stahl's theory concerning vitriolic acid was still current among phlogistians at this period. He (1766, p. 18) had stated that "Chemists cannot agree on the decision as to whether [vitriolic] acid is already in the sulfur, or if it is produced by the deflagration". In a particularly noteworthy experiment, he burned sulphur in open conditions; the sulphur appeared to be destroyed, while the result was an acid - volatile vitriolic acid (Stahl 1766, pp. 159-160), which was unstable and slowly changed into vitriolic acid, ${ }^{6}$ which when undiluted was a much stronger acid than volatile vitriolic acid (Macquer 1766, v.1. p. 18). Stahl's interpretation started from the assumption that there was a principle of inflammability: he (1766, p. 18) argued that since sulphur burned easily it contained phlogiston, that vitriolic acid did not burn so it did not contain phlogiston, that accordingly the process of burning sulphur was a decomposition involving the emission of phlogiston, that the burning of sulphur alone did not complete the process of dephlogistication, and that the subsequent slow change also involved dephlogistication.

Stahl's overall theory was that there was a universal acid, which for Stahl was vitriolic acid (Juncker 1757, v. 5, p. 62; Macquer 1766, v. 1, p. 19). For example, Stahl's theory of nitrous acid was that it differed from vitriolic acid in the same ways that volatile vitriolic acid did, from which he inferred that nitrous acid was also a compound of phlogiston and the vitriolic acid but combined in a different manner (Juncker 1757, v. 5, p. 181; Macquer

${ }^{6} \mathrm{SO}_{2}$ in acqueous solution, and $\mathrm{H}_{2} \mathrm{SO}_{4}$, respectively. 
1766, v. 1, pp. 13, 20). Becher's view of the marine acid was that it was a compound of vitriolic acid with the mercurial earth (Juncker 1757, v. 5, p. 237; Macquer 1766, v. 1, p. 5); another view was that the nitric and marine acids were the same (Stahl 1723, p. 357). Stahl considered that phosphorus was a compound of the marine acid and phlogiston (Juncker 1757, v. 4, p. 377) and that phosphorus was a kind of sulphur except that its acid was more subtle.

Macquer theorised that the reason for the instability of volatile vitriolic acid was that it contained some phlogiston (1766, v. 1, p. 17) which had little or no tendency to unite to water $(1766$, v. 2 , p. 205) and that the presence of water in this acid drove out the remaining phlogiston to form the vitriolic acid (Macquer 1766, v. 1, p. 20). This was scarcely consistent with Macquer's (1766, v. 1, p. 20) argument that vitriolic acid had a great facility to combine with phlogiston, even when the acid was very diluted. Macquer (1766, v. 1, pp. 5-6) noted that Stahl claimed to have transmuted nitrous and marine acids into vitriolic acid and vice versa, but had not published his experiments, and so Macquer reasonably judged that the interrelations of these acids remained as unresolved problems.

Cavendish's (1766, p. 145) theory followed Stahl's theories concerning volatile vitriolic acid and vitriolic acid. Although he later used pure air in his experiments concerning acids, it did not feature in his (1784a, p. 136) theories, which extended his 1766 views by adding that nitrous acid plus phlogiston also made phlogisticated air. His retained mainly-Stahlian theories of acids were incompatible with his new views that inflammable air was water plus phlogiston and that dephlogisticated air was dephlogisticated water. Additional problems of these views have been discussed in the first paper (Blumenthal and Ladyman 2017, pp. 247-248 and pp. 259-260).

Sage's (1777, v. 1, p. vii) theory was that phosphoric acid was the universal acid, and that not only when it was combined with phlogiston did it form phosphorus $(1777, \mathrm{v} .1$, p. 3) but with the further addition of water it formed air (1777, v. 1, p. xii) and with phlogiston and air it formed fire (1777, v. 1, pp. xix-xx). Baumé's (1773) theory was that "each acid has its individual origin, and there is no universal acid".

Scheele's (1931, p. 162) early theory included that fixed air plus phlogiston probably made pure air which was the basis of all acids. His (1931, pp. 103-104) theory also followed Priestley's early theory by including that different types of air could be produced by phlogisticating nitrous acid. The opposite process was at work in producing what he called "dephlogisticated marine acid". 7 Scheele's later theory (1931, p. 286) was that "it is very probable that if we could entirely deprive of water the acid of nitre, this acid would then approach very nearly to the saline principle". Accordingly, Scheele's view of dephlogisticated marine acid was an anomaly relative to both of Scheele's differing early and late more general views on acids.

Bergman's (1785, pp. 201-202) theory was that it was phlogiston that caused acidity. By contrast, Priestley's (1794, pp. 8-9) theory was that phlogiston was the principle of alkalinity. Priestley $(1788$ b, p. 314) hypothesised that there was a "principle of acidity" that was an unisolatable component of dephlogisticated air, of which the other component was water, and he (1793, p. 38) hypothesised that nitrous acid, like "nitrous air, fixed air, phlogisticated air, alkaline air, and probably all the other kinds of air with which we are acquainted, except the dephlogisticated and the inflammable, are composed of dephlogisticated air and phlogiston'.

\footnotetext{
7 Now chlorine. The interpretation in the secondary literature that in this case, phlogiston was equivalent to hydrogen, does not take into account that Scheele thought that pure air was the basis of all acids.
} 
Kirwan (1789, p. 286) thought that vital air only became the acidifying principle and a constituent part of calces after it had united with inflammable air to form fixed air and that only acids united to other substances (Kirwan 1789, p. 314), despite the fact that his view also involved inflammable air uniting to other substances such as the bases of metals, sulphur and phosphorus. Kirwan's hypotheses on acids included (1789, p. 126) that marine acid consisted of a peculiar basis united to phlogiston and a certain proportion of fixed air, while dephlogisticated marine acid consisted of the peculiar basis with an excess of fixed air.

Westrumb (1790) worked on dephlogisticated marine acid and argued (1791) about the substance with the antiphlogistians Arbogast (1791) and Berthollet (1791). Westrumb's (1791, p. 30) conclusion was that this substance contained the base of muriatic acid, water, matter of heat, and a considerable quantity of dephlogisticated manganese (calx). Among other issues, this exemplified that the phlogistians in general were far from accepting Scheele's view of this acid.

By contrast, Lavoisier had produced a series of consistent theories, based on experiments, about acids. He (1776, pp. 130-134) undertook the analysis and synthesis of nitrous acid, and inferred that nitrous acid was composed from nitrous air plus pure air plus water. He (1778, p. 251) identified that more than one type of nitrous acid could be produced, using varied amounts of pure air, and that the greater the content of pure air, the more acidic was the resulting compound. He $(1777 \mathrm{c})$ showed pure air could also be released from vitriolic acid. He (1778, p. 250) inferred that oxygen with carbon formed carbonic acid ("fixed air"), with sulphur it formed vitriolic acid, with nitrous air it formed nitrous acid, with phosphorus it formed phosphoric acid. These conclusions related well to the experimentally available constituents, in the sense that content of heat was measurable separately and did not affect the measurement of the weight of constituents, and given that he was mostly talking about acid anhydrides. In effect, most of the then-known acids could be experimentally demonstrated to contain oxygen. In all such cases, Lavoisier's detailed compositional theory was not affected by his views on the nature of acidity.

Lavoisier's (1778, p. 250) theory that oxygen was the acidifying principle was rational at that time, in that several then-known acids could be experimentally demonstrated to contain oxygen, and in that greater content of oxygen correlated with greater acidity. At that time, water and marine acid were not known to have been decomposed. It was in this context that Berthollet (1785) undertook his attempt to show that dephlogisticated marine acid was a compound of oxygen with marine acid.

However, Berthollet (1788) showed that dephlogisticated marine acid had different properties from those which were usual to acids, he (1789) concluded that the constituents of prussic acid did not include oxygen, and he (1791) demonstrated that the chemical behaviour of metallic oxides did not support Lavoisier's oxygen theory of acidity. This led to his (1789a) formulation of a wider Lavoisian view on acidity. Berthollet argued that substances might contain a large quantity of oxygen without being acidic: water was a striking example. There were still several acids of which there was no evidence that oxygen was a constituent - muriatic acid, fluoric acid, boracic acid, and lithic acid, ${ }^{8}$ while it was almost certain that prussic acid did not contain oxygen. Berthollet (1789a, pp. 67-68) suggested that the term "oxygen" might be a misnomer if it were not present in all acids, but stated that it was not necessary to depend too closely on the etymology of words based on dead languages. Berthollet proposed the re-definition of "acid" as a class

\footnotetext{
8 The uncertainty at the time becomes clearer when it is realised that boracic acid and lithic (uric) acid were eventually shown to contain oxygen.
} 
of substances that united with another class of substances (bases) to form compounds (salts).

Yet what Berthollet had not done was to produce a theory of the nature of acidity. It remained the case that where a substance formed more than one acid with different amounts of oxygen, greater content of oxygen correlated with greater acidity. At the time, Lavoisier's theory was the only theory of acidity that appeared to correlate with experimental findings concerning greater or lesser acidity, that did not have the problem that supposed constituent substances were heavier than supposed compounds containing these supposed constituents, that did not have the problem that some supposed compounds could not be analysed into their supposed constituents while some supposedly simple(r) substances could be decomposed, and that did not have the problem that pure air (oxygen) was a substance that was necessarily used or produced in experiments on the synthesis or analysis of these substances but it was not represented in the theory.

In overall terms it could be seen in 1790-1791 that the problem of the nature of acidity had not been resolved. There were numerous mutually-incompatible phlogistic theories, all of which were effectively experimentally untestable or untested in that they involved phlogiston or a hypothesised principle of acidity that was not experimentally available. The new chemistry retained two alternative concepts of acidity in 1790, both of which were based on copious experimental evidence, and which had different merits and problems. It was rational to judge that each of the theories of acidity in the new chemistry was more soundly based than any of the phlogistic theories.

\section{Theory comparisons concerning the natures of heat, change of state, expansion, fluidity, and phlogiston}

Stahl's theory was still influential, even if all the later phlogistic views differed from it to some extent. Stahl held that phlogiston in its free form permeated everywhere in the universe, but it wasn't heat and it did not cause change of state. Stahl thought that heat was the motion of particles. In his initial theory, phlogiston, water and the mercurial and vitrifiable earths existed in all three states (Juncker 1757, p. 146), but for all other substances the gaseous state was caused by content of water (Juncker 1757, pp. 132-133). In the full collection of Stahlian views, elasticity could also be caused by content of water or of the mercurial earth (Juncker 1757, p. 113), and the content of phlogiston caused a substance to be volatile (Juncker 1757, p. 135). In effect, it was not clear which of these principles caused expansion or contraction for particular substances. Phlogiston was a constituent of many substances (Juncker 1757, p. 135), but could not collected in isolation.

Macquer (1766) held that heat was material and the phlogiston was a compound not a principle, but later (1778, pp. 3:122 and 3:132) changed his views drastically by going back to Stahl's view that heat was the motion of molecules, and adopting Homberg's (1705) view that matter of fire was the matter of light. Scheele and Bergman held a material theory of heat, and Bergman (1784, pp. 341-342) clarified that the kinetic theory of heat is "at present held to be totally improbable'. Scheele's (1931, p. 286) later view was that heat was a combination of the saline principle with phlogiston. He (1931, pp. 286-287) thought that phlogiston was the cause of the elasticity of the air. Priestley (1790c, p. 535) thought that water was the basis of all kinds of air and provided their elasticity, but he (1790c, p. 539) also said that something communicated by heat was a constituent principle of every kind of air.

Wiegleb (1784) had remarked on the differing opinions held on the nature of phlogiston by Becher and Stahl (an earth), Stahl (elementary fire), Baumé (elementary fire and a subtle 
earth), Macquer (pure fire), Guyton de Morveau (fixed fire), Scheele (a peculiar element), Buffon (air and fire), and Kirwan (inflammable air). Leonhardi (1788, v. 1, pp. 657-672) gave several reasons why phlogiston was not bound fire or bound matter of heat, or the matter of light, or heat brought into rest by some fixative such as earth. He favoured a theory with some echoes of Scheele's, in which the matter of heat in phlogiston was bound by some saline body. Leonhardi $(1789$, v. 3, pp. 434, 452) argued against Stahl's theory that the addition of phlogiston makes bodies lighter.

Elliott (1780, pp. 92-110; 1782, pp. 83-84) proposed that the light of flame was phlogiston, and heat was produced from the union of phlogiston and air; phlogiston and fire mutually replaced each other in substances. Morgan (1785) proposed that light is present in combustibles in a combined form and is expelled when they are decomposed by heat or other means. Marchand (1787, pp. 23, 33, 41, 59, 78, 93) argued that inflaming matter is light, which was different from fire, and that a negatively electrifiable body contained phlogiston, whereas a positively electrifiable body contained fire. Gren held a material theory of heat, and (1788c, pp. 299 and 406) thought that phlogiston was a combination of the matters of heat and light. The constitutions that Gren (1790, p. 457) proposed for substances always included Wärmestoff (matter of heat) and often also contained Brennstoff (phlogiston, matter of fire).

Against these phlogistic positions, Lavoisier (1774) had established that evident transfer of a substance in calcination that had previously been taken as providing some indirect confirmation of the existence of phlogiston, was now evidently of air, in that the weight gain of calces was approximately equal to the weight of air that they had absorbed during calcination. Lavoisier (1785, pp. 634-637) also rightly noted that by now several chemists had established their own particular phlogistic doctrines, in which the name of phlogiston had been conserved, but in which no-one had rigorously defined phlogiston, and each chemist had attached their own properties to it. None of the phlogistic explanations covered the range of matters while being internally consistent, and the current phlogistic systems were mutually contradictory and irreconcilable.

It could be understood at the time that the central, stable and firmly experimentally based part of Lavoisier's new chemistry on these issues was that expansion, contraction and change of state were caused by heat. These points were underlain (1777d, p. 215) by experimental evidence that bodies expanded or contracted with temperature changes, and (1777d, pp. 215-216) by the evidence of cooling of solids by evaporation of liquids from their surfaces. These points were absolutely fundamental to the new chemistry in that it was no longer necessary to hypothesise that substances in different states were differing substances.

However, the clarity of these points was at least partly masked for many participants by Lavoisier's successive published versions of his theory of heat, and by the differing expression he used about heat. Lavoisier (1777d, pp. 212-213) originally held a material theory of heat, following the French tradition led by Macquer. Yet this version involved a very subtle fluid which he called "igneous fluid, matter of fire, heat and light", which lumped together concepts which other chemists deemed to be separate. Macquer's (1778) drastic change to a kinetic theory of heat and to the theory that phlogiston was matter of light made it necessary for Lavoisier to change his theory in these respects. In effect, Lavoisier had to work out a way of holding a stable theory of change of state which would not be affected by future changes in the fortunes of the current theories of heat. Accordingly, Lavoisier and Laplace (1784, pp. 285-287) proposed that the terminologies of the material and kinetic theories of heat were equivalent. 
Their proposal was then not taken into account by Guyton in his section in the Nomenclature, in which he stated that heat "is generally thought to be a sensation produced by a material principle, and we have expressed this latter by the word caloric" (Guyton et al., 1787, p. 22). Accordingly, Lavoisier provided a different definition in the Traité. He (1790, pp. 4-5) defined caloric as the "cause of heat": he stated that "we are not obliged to suppose this to be a real substance; it being sufficient... that it be considered as the repulsive cause... which separates the particles of matter from each other". He stated that his definition "possesses this... advantage, that it accords with every species of opinion, since... we are not obliged to suppose this to be a real substance;... so that we are still at liberty to investigate its effects in an abstract and mathematical matter". For practical purposes he (1790, p. 17) stated that "comparisons with sensible bodies are of great use in assisting us to form distinct notions of abstract ideas".

It was possible to identify that the key to the interpretation of Lavoisier's theory of caloric was his (1790, pp. 182-183) indication that he had not constructed any table of the combinations of light and caloric with the various simple and compound substances, because the nature of these combinations was not sufficiently known. While caloric could become fixed in bodies, its principal function was to surround and penetrate all bodies in nature in every way, and to cause change of state. That is to say, its actions on other substances were unlike those of any other substance, and were principally physical rather than chemical. Light and caloric were the only two supposed substances listed in his table of simple substances for which he provided reasons why they did not figure in the tables of chemical compounds. In addition, it could be identified that Lavoisier continued to use both the material and kinetic explanations in an intertwined fashion (Morris 1972, p. 35).

In overall terms it was possible to see in 1790-1791 that the new chemistry had resolved the issue of change of state as being caused by heat, and that this was based on experimental evidence. By contrast, Lavoisier's most recent theory of heat, with its balancing act between the material and kinetic theories of heat, and its material theory of heat which involved a substance which acted in a manner that was unlike any other substance, was clearly questionable, although the numerous mutually-incompatible phlogistic theories did not offer a viable competitor.

\section{Theory comparisons in terms of simplicity, consistency, scope, the potential for further discoveries, testability, the solution of problems, and overall strategies}

Some of the participants referred to general epistemic criteria of which some are similar to modern suggestions concerning epistemic virtues. This section involves comparisons in terms of some of these criteria, and takes into account all the comparisons given in the previous sections as well as the history given in the previous paper.

Several previous authors had invoked the criterion of simplicity. Priestley (1777, pp. 242-243) noted that Newton's rules of philosophising "will not authorise us to multiply causes, or kinds of substances, without necessity". From this point of view, it is clear from the material in the previous sections that by $1790-1791$, the new chemistry was far simpler than the aggregate of the phlogistic theories. In particular, it was both welldeveloped and clearly simpler in terms of the understanding and naming of compound substances. Stahl's initial four-principle theory had involved fewer principles, but later phlogistic theories included an indefinite number of earths about which it was not clear whether or not they were simple. Macquer (1764) could not say how experimentally- 
available substances were related to his proposed four elements, nor how his multiple earths did so. It was not clear how many basic principles Cavendish's (1784a) theory was supposed to contain. Priestley's $(1788 \mathrm{a}, \mathrm{b}, 1789,1791)$ theory of gases effectively had three principles, water, phlogiston and the "principle of acidity", while his (1794, pp. 8-9) wider theory had eight principles plus an unspecified number of apparently simple earths.

Among authors who stressed the virtues of consistency was Priestley, who (1774b, p. 27) stated that a "loose and incoherent... system... ought not to be adopted without the most urgent necessity". Yet in 1790-1791 it could be seen that in overall terms the set of the late phlogistic theories, as well as Priestley's own output on several topics in chemistry, demonstrated an exceptional lack of any consistency whatsoever. In comparison, the Traité gave a generally consistent system of chemical composition, even if some issues could not be resolved at that time.

Priestley $(1769$, p. 418$)$ stated that "General propositions... are contrived ... in order to comprehend things clearly, and to comprise as much knowledge in the smallest compass". This suggested that wide scope of view needed to be linked to other criteria such as simplicity and consistency. Yet the phlogistic theories from 1766 onwards had wide scope only if account is taken of Priestley (1774) speculations, his (1794, pp. 8-9) speculative theory and such theories as Eliot's $(1780,1782)$ and Marchand's $(1787)$, but in that case they were very poor in terms of simplicity and consistency. For example, Priestley (1774, p. 275) persisted in putting forward speculations connecting phlogiston with electricity "however chimerical soever they may be thought to be", yet in Priestley's (1794) speculative theory electricity and phlogiston were separate principles. Cavendish's (1784a) theory had a limited scope, and the scope of Cavendish's (1784a) theory of water was even smaller. In comparison, it could be clearly understood that the theory of chemical composition in the Nomenclature and the Traité already covered the known experimentallyavailable chemical substances and was designed to be extendable to cover the whole of compositional chemistry.

Guyton (1786, p. 625) said that "in the physical sciences, the truth is everything; here is the unique goal towards which all efforts must be directed". Yet there was no sure way of arriving at truth in practice. One of the proxies that were used to estimate likely truth at the time was testability. Berthollet's letter of 4 May 1785 to Guyton stated that the new theory when compared with phlogiston had "substituted the data of experiment for a useless hypothesis". Very few of the many published phlogistic theories were testable, the main exception being the theory that phlogiston was inflammable air, and where any phlogistic theory was potentially testable either tests could not actually be undertaken or the tests failed to confirm the theory. In comparison, the new theory was almost fully testable, in that the "simple substances" (other than heat and light) were experimentally investigable by weight, while their level of heat was investigable in terms of temperature, even though the idea of caloric as the "cause of heat" was not experimentally investigable. It is noteworthy that those of the phlogistians including Cavendish who could measure weight accurately, tended not to do so on significant occasions, which can be correlated with the potential for weight measurement to produce results which would be against a phlogistic theory. By contrast the new chemistry made a major impression on other sciences, in that Cuvier (1810, p. 390) stated concerning the natural sciences that that "Experiment alone, precise experiment, carried out with attention to weight, measure, calculation and a comparison of all the substances used and all the substances obtained, is today the only legitimate way of reasoning and demonstration".

Concerning the most promising route to future discoveries, Delambre (1810, pp. 31-32) in his report on the mathematical sciences stated that "the revolution recently brought 
about in chemistry could not happen without turning many experimentalists a little out of their ordinary course, when they saw in a neighbouring science a road opened that promised more numerous discoveries". Before 1774 the phlogistic theories had been the only way of understanding the links between composition and calcination and vitriolic acid, and as such were perceived as being fertile. After 1787, it could be readily understood that the new theory both predicted the existence of new compounds on an unprecedented scale, and was able to incorporate new simple substances and compounds immediately into a structured knowledge of chemical composition that potentially applied to the whole of chemistry. It was the rapid advances in chemistry after 1789 which led Cuvier (1810) in his report on the recent progress of the natural sciences to devote twice as much space to chemistry as to any other science.

Concerning the solution of problems, Berthollet's letter of 4 May 1785 to Guyton showed that he was influenced by the information on the composition of water, which now gave an "explanation of the formation of inflammable air", and by the experimental work which now showed the correctness of Lavoisier's ideas on the nature of nitrous acid. Lavoisier (1777e, p. 225) viewed "systems in science [as] ... methods of approximation which put us on the route to solving a problem: they are hypotheses which, successively modified, corrected and changed to the extent that they are disconfirmed by experience, ... lead ... via exclusions and eliminations, to the knowledge of the true laws of nature". It was potentially understandable by taking an overall view of the history of the new chemistry, that it had enjoyed a succession of solutions of problems. The issue concerning the particular type of air that was released during the reduction of mercury calx had been resolved by work which built on information from Priestley, and this also aided Lavoisier (1775/8, pp. 127-128) to infer accurately that fixed air was composed of pure air combined with the main constituent of charcoal. In 1775, Priestley's work on the types of air that were related to nitrous acid, had enabled Lavoisier (1776, pp. 130-134) to re-do the experiment and to re-interpret the results accurately concerning the composition of nitrous acid. In 1783, Blagden's information about Cavendish's identification that the combustion of pure air and inflammable air produced water, had enabled Lavoisier to solve several matters which had previously been issues for him concerning composition. In 1785, Cavendish's (1784a) paper provided the Lavoisians with the answer concerning why their large-scale experiment on the combination of pure air and inflammable air included a small amount of acid, and how this could be avoided. Also in 1785, Cavendish's identification that dephlogisticated air and phlogisticated air were both necessary to produce nitrous acid was rightly re-interpreted by the Lavoisians as indicating that both were constituents of the acid. In 1791, Kirwan's (1791) published letter to Crell showed that he was influenced by the progressive nature of the new theory in terms of Berthollet's (1789b) criticism of Priestley's work, Guyton's (1786) article on Air, and the experiment on combining vital air with inflammable air by Fourcroy and colleagues (in Lavoisier et al. 1790).

On taking a wide view in 1790-1791, it was possible to understand that the individual participants' strategies for attempting to create theories had been crucial to their success or lack of it. As Guyton (1786, pp. 633-634) pointed out, due to the new chemistry, chemists would "no longer be obliged to regard phlogiston, sometimes as a substance of which the weight needed to be taken into account in analyses but at other times as the most subtle of bodies; to suppose it to be in one case not capable of permeating through vessels but in other cases as capable of penetrating them as heat; to attribute to it contrary properties depending on the circumstances, without being able to reconcile such cases; and to take as an explanation the fiction which identifies substances as diverse as vital air, harmful air, nitrous air, inflammable air and fixed air, and which makes such enormous differences 
depend only on a little more or a little less phlogiston". He noted that "as soon as one abandons the hypothesis of a unique combustible, one sees everything return to conformity with the nature of things: each combustible is a being of its own sort, which results in an essentially distinct product". Cuvier (1810, p. 78) stated about Lavoisier that "before him, the particular phenomena of chemistry could be compared to a sort of labyrinth of which the deep and tortuous routes had all been explored by many industrious men; but ... the relations between these and the whole, could not be perceived except by the genius who knew how to elevate himself above the edifice and to understand its layout with the eye of an eagle".

\section{Theory comparisons concerning "losses" by a theory of parts of a former theory}

Berthollet's letter of 4 May 1785 to Guyton stated that "while M. Lavoisier could not give any explanation of the formation of inflammable air and while he had false ideas on the nature of nitrous acid, I defended the theory of phlogiston". That is, prior to the experiment on the combination of dephlogisticated air and inflammable air which produced water and which enabled Lavoisier to solve these issues in the new chemistry, Lavoisier's theory had apparently lost some explanations relative to those that apparently worked in previous theories, and Berthollet's change of theory occurred when this was no longer the case.

Yet much bigger losses of useful information and theories had occurred previously. Some of these were due to Stahl's theory, but others were arguably due to the lack of widely acceptable theories in chemistry together with the lack of good textbooks and the restricted circulation of publications. For example, while Jean Rey (1630) knew and quoted the work of Geber, Cardano, Scaliger, Fuchsius, Cesalpinus and Libavius, his own book in which he argued that the increase in weight of calces comes from air which becomes mixed with the calx and attaches to its most minute particles, was very little known. This was arguably because of its limited circulation and because its views were not collected into later textbooks. John Mayow was appointed to the Royal Society, yet his (1674) theory had a few echoes but then became very little known, other than via a quote in Stephen Hales's (1727) book. One of the causes of the neglect of Mayow's work was the much wider attention paid to the views of Robert Boyle, and it is arguable whether Boyle's views or limited circulation and lack of dissemination in textbooks was the main cause.

However, Fourcroy (1796, p. 362) identified that the enthusiasm for Stahl's theory caused the lack of attention paid to Hales's book, despite the work having been translated into French by the celebrated Buffon (Hales 1735). The absorption of air or of any other material during calcination was incompatible with Stahl's theory of phlogiston, so as previously stated, Stahl argued throughout his life that air did not have the least power to take part in chemical combinations. Stahl argued against Boyle's views but not any other views on the topic. This loss of information and theories concerning the absorption of a substance during calcination continued, in that while Macquer's textbook included both Stahl's concept of phlogiston and the inconsistent concept that air could be absorbed in solid substances, Macquer taught a phlogistic theory of calcination.

\footnotetext{
${ }^{9}$ Duhem (1991, p. 197) later put Cuvier's point more generally, by indicating that when there is a major problem or set of problems with an existing theory, it can be necessary to consider the whole of the discipline in order to work out what is wrong and work out potential solutions. In contrast concerning the phlogistians' practices, Duhem (1916, p. 32) pointed out that the "too-easy escape-route" of hypothesising that substances passed through glass "permitted experimentalists to neglect to examine certain difficulties, but it was this examination that would have led them to discover the key to the theory of chemistry".
} 
It had been evident since 1774 that Lavoisier's work on the absorption of air in calcination had rectified the former loss of information on this in Stahl's theory. This was basic to the new compositional structure, which catered for all then-known substances. In addition to this comprehensiveness, the new chemistry was deliberately designed to be adjustable in the light of future new evidence, and both of these aspects contributed to reducing the previous widespread losses of evidence and theories. Lavoisier's Traité and subsequent textbooks that were influenced by it (e.g. Thomson 1810; Murray 1819) were drastically different from Macquer's (1764) and Guyton et al.'s (1778), in that they were no longer mainly composed of descriptions of experiments, and in that they both consisted of structured, acceptable and teachable information on chemistry and showed a continuing and rapid increase in that information.

\section{Theory comparison and theory choice at this period}

This paper has given a relatively comprehensive guide to the comparisons that could have been made between the available theories at this period, although there are additional comparisons that were made at the time. There were differences between the participants in terms of their access to information, their time and inclination to undertake such comparisons, their prior commitments or prejudices, their relations with others in social groups with various commitments, and their priorities in terms of defending past publications or achieving new understanding. Consequently, there was a very wide variation in the reasons that they gave for their theory choices.

The relative advantages of the new chemistry were most readily apparent to those with no prior commitments, in cases where it was offered to them as a free choice. Chaptal in his letter of 6 February 1788 to Lavoisier (in Lavoisier 1993, pp. 122-123) clarified that he was now using the new Nomenclature, and that "mon cours est suivi avec un enthousiasme dont on a peu d'examples". Black in his letter of 24 October 1790 to Lavoisier (in Lavoisier 1997, pp. 185-186) stated that his students "in general embrace your system and begin to make use of the new nomenclature, in proof of which I send you two of their Inaugural Dissertations".

During this period, the published record suggests that the participants did not blindly adhere to theories. On the contrary, the relative status of theories and of their component hypotheses was reassessed as new experimental evidence was received or as new publications illuminated new evidence or differing interpretations, even if and when participants chose to retain their previously-favoured theories. Guyton (1786, pp. 626-627) stated that in chemistry discoveries were continually being made, and the leading chemists were divided on the most important points of theory, so his own consideration of the issues had been "slow and circumspect". The very widespread theory change, that actually took place between 1785 and roughly 1795 , occurred due to a large number of individual reactions as the balance between the evidence for the comprehensive relative success of the new chemistry, and the evidence for the failure of the set of attempts to produce a revised phlogistic competitor, changed and became clearer.

Few of the early assessments by participants who were not antiphlogistians, matched Kopp's (1845, p. 155) recognition concerning the late phlogistic theories that during this period "there was only agreement concerning the existence of something called phlogiston... This situation of true anarchy lasted among the phlogistians from about 1780 to 1800'. Among the best of the earlier assessments concerning theory comparison and choice at this period was by Thomson (1830, v. 2, p. 133), who had studied at Edinburgh under Black in the $1790 \mathrm{~s}$. He judged that the "extraordinary rapidity with which the new 
chemical language came into use was doubtless owing to two circumstances:... the very defective, vague and barbarous state of the old chemical nomenclature... (and) the superiority of Lavoisier's theory over that of Stahl. The subsequent progress of the science has betrayed many weak points in Lavoisier's opinions; yet its superiority over that of Stahl was so obvious, and the mode of interrogating nature introduced by him was so good... that no unprejudiced person, who was at sufficient pains to examine both, could hesitate about preferring that of Lavoisier".

Acknowledgements Funding for the work of Geoffrey Blumenthal was provided by Arts and Humanities Research Council (Grant No. 1225327).

Open Access This article is distributed under the terms of the Creative Commons Attribution 4.0 International License (http://creativecommons.org/licenses/by/4.0/), which permits unrestricted use, distribution, and reproduction in any medium, provided you give appropriate credit to the original author(s) and the source, provide a link to the Creative Commons license, and indicate if changes were made.

\section{References}

Arbogast, L.F.A.: Nouvelles experiences sur la Combustion de différens Corps dans l'acide muriatique déphlogistiqué (oxigéné), par M. Westrumb, [avec] Remarques. Ann. Chim. 6, 240-274 (1791)

Baumé, A.: Chymie Expérimentale et Raisonnée. Didot, Paris (1773)

Bayen, P.: Essai d'expériences chymiques, faites sur quelques précipités d mercure, dans la vue de découvrir leur nature. Observations sur la Physique 3, 129-145 and 280-295 (1774)

Bayen, P.: Essais chymiques, ou expériences faites sur quelques précipités d mercure, dans la vue de découvrir leur nature. Observations sur la Physique 5, 147-160 (1775)

Bergman, T.: Physical and Chemical Essays. Trans. E Cullen. Murray, London

Bergman, T.: Dissertation on Elective Attractions. Murray, London (1785)

Berthollet, C.-L.: Mémoire sur l'acide marin déphlogistiqué. Histoire de l'Académie Royale des Sciences, avec Mémoires 1785, 276-295 (1788)

Berthollet, C.-L.: Mémoire sur l'acide Prussique. Histoire de l'Académie Royale des Sciences, avec Mémoires 1787, 148-162 (1789)

Berthollet, C.-L.: Observations sur la combinaison des oxides métalliques avec les alkalis et la chaux. Histoire de l'Académie Royale des Sciences, avec Mémoires 1788, 728-741 (1791)

Berthollet, C.-L.: Suite des expériences sur l'acide sulfureux. Ann. Chim. 2, 54-72 (1789a)

Berthollet, C.-L.: Considérations sur les Expériences de M. Priestley. Ann. Chim. 3, 63-114 (1789b)

Berthollet, C.-L.: Observations sur quelques faits que l'on a opposes à la doctrine anti-phlogistique. Ann. Chim. 11, 3-26 (1791)

Blumenthal, G., Ladyman, J.: The development of problems within the phlogiston theories, 1766-1791. Found. Chem. 19, 241-280 (2017)

Cavendish, H.: Three papers, containing experiments on factitious air. Philos. Trans. R. Soc. Lond. 56, 141-184 (1766)

Cavendish, H.: Experiments on air. Philos. Trans. R. Soc. Lond. 74, 119-153 (1784a)

Cavendish, H.: Answer to Mr. Kirwan's remarks upon the experiments on air. Philos. Trans. R. Soc. Lond. 74, 170-177 (1784b)

Cavendish, H.: Experiments on air. Philos. Trans. R. Soc. Lond. 75, 372-384 (1785)

Cuvier, G.: Rapport historique sur les progrès des sciences naturelles depuis 1789, et sur leur état actuel. Imprimerie Impériale, Paris (1810)

Delambre, : Rapport sur les progress des sciences mathématiques depuis 1789 et sur leur état actuel. Imprimerie Impériale, Paris (1810)

Duhem, P.: The Aim and Structure of Physical Theory. Trans. P. Wiener. Princeton University Press, Princeton (1991)

Duhem, P.: La chimie est-elle une science française? Hermann, Paris (1916)

Elliott, J.: Philosophical Observations on the Senses of Vision and Hearing. Murray, London (1780)

Elliott, J.: Elements of the Branches of Natural Philosophy. Johnson, London (1782)

Fourcroy, A.-F., Vauquelin, L., Séguin, A.: Mémoire sur la Combustion du Gaz Hydrogène dans des Vaisseaux clos. Ann. Chim. 8, 230-307 (1791) 
Fourcroy, A.-F.: Chimie. In: Fourcory, A.-F., Chaussier, F., Duhamel, J.-P.-F. (eds.) Encyclopédie Méthodique, Chimie, Pharmacie et Métallurgie, tome troisième, pp. 262-781. Agasse, Paris (1796)

Gren, F.A.C.: Systematisches Handbuch der gesammten Chemie, vol. 1. Waisenhaus, Halle (1787)

Gren, F.A.C.: Versuche und Beobachtungen über die Entstehung der fixen und phlogistichen Luft. Beyträge zu den chemischen Annalen, 2, 296-330, 424-444 (1787) and 3, 229-259 (1788a)

Gren, F.A.C.: Über Luft, Brennstoff und Metalkalke. In: Westrumb, J. (ed.) Kleine physikalisch-chemische Abhandlungen, v. 3, pt. 1, 415-479. Müller, Leipzig (1788b)

Gren, F.A.C.: Grundriss der Naturlehre zum Gebrauch akademische Vorlesungen entworfen. Halle (1788c)

Gren, F.A.C.: Systematisches Handbuch der gesammten Chemie zum Gebrauch seiner Vorlesungen entworfen, Zweiten Theiles zweyter Band. Halle (1790)

Grison, E., Goupil, M., Bret, P., eds.: A Scientific Correspondence During the Chemical Revolution: LouisBernard Guyton de Morveau and Richard Kirwan, 1782-1802. Office for History of Science and Technology, Berkeley (1994)

Guyton de Morveau, L.-B.: Digressions académiques, ou Essais sur quelques sujets de Physique, de Chymie et d'Histoire naturelle. Frantin, Dijon (1772)

Guyton de Morveau, L-B.: Second avertissement. In: Guyton de Morveau, L.-B., Maret, H., Duhamel, J.-P.F. (eds.) Encyclopédie Méthodique, Chimie, Pharmacie, Métallurgie, tome premier, pp. 625-664. Panckoucke, Paris (1786)

Guyton de Morveau, L.-B., Lavoisier, A.-L., Berthollet, C.-L., Fourcroy, A.: Méthode de Nomenclature Chimique. Cuchet, Paris (1787)

Guyton de Morveau, L-B., Maret, H., Durande, J.B.: Élémens de chymie, théorique et pratique. Frantin, Dijon (1777-8)

Hales, S.: Vegetable Staticks. London: Innys (1727) trans. Buffon as La statique des vegetaux et l'analyse de l'air. Paris: Vincent (1735)

Homberg, W.: Suite de Essays de Chimie. Article Troisième. Du Souphre Principe. Histoire de l'Académie Royale des Sciences, avec Mémoires, 88-96 (1705)

Juncker, J.: Conspectus Chemiae theoretico-practicae in forma Tabvlarvm repraesantatvs... e Dogmatibvs Becheri et Stahlii potissimvm explicantvr..., 2nd ed., trans. Demachy as Élémens de Chymie suivant les Principes de Becker et de Stahl. Hardy, Paris (1757); References are to vol 1 unless otherwise indicated

Kirwan, R.: Remarks on Mr. Cavendish's experiments on air. Philos. Trans. R. Soc. Lond. 74, 154-169 (1784a)

Kirwan, R.: Reply to Mr. Cavendish's answer. Philos. Trans. R. Soc. Lond. 74, 178-180 (1784b)

Kirwan, R.: An Essay on Phlogiston and the Constitution of Acids. Johnson, London (1789)

Kirwan, R.: Vom Hrn. Ritter Kirwan in Dublin. Chemische Annalen 1791:1, 425-426 (1791)

Kopp, H.: Geschichte der Chemie, vol. 3. Vieweg, Braunschweig (1845)

Lavoisier, A-L.: Opuscules Physiques et Chymiques. Paris (1774). Page refs to Oeuvres de Lavoisier, vol 1. Paris, Imprimerie Imperiale (1864)

Lavoisier, A.-L.: Mémoire sur la nature du principe qui se combine avec les métaux pendant leur calcination et qui augmente le poids (1775/8) in Oeuvres de Lavoisier, vol. 2, pp. 105-121. Imprimerie Imperiale, Paris (1862)

Lavoisier, A.-L.: Mémoire sur l'existence de l'air dans l'acide nitreux, et sur les moyens de décomposer et de recomposer cet acide (1776) in Oeuvres de Lavoisier, vol. 2, pp. 129-138. Imprimerie Imperiale, Paris (1862)

Lavoisier, A.-L.: Mémoire sur la combustion du phosphore de Kunckel, et de la formation de son acide. (1777a) in Oeuvres de Lavoisier, vol. 2, pp. 139-152. Imprimerie Imperiale, Paris (1862)

Lavoisier, A.-L.: Expériences sur la respiration des animaux. (1777b) in Oeuvres de Lavoisier, vol. 2, pp. 174-183. Imprimerie Imperiale, Paris (1862)

Lavoisier, A.-L.: Mémoire sur la dissolution de mercure dans l'acide vitriolique, et sur la résolution de cet acide en acide sulfureux aériforme et en air éminement respirable. (1777c) in Oeuvres de Lavoisier, vol. 2, pp. 194-198. Imprimerie Imperiale, Paris (1862)

Lavoisier, A.-L.: De la combinaison de la matière du feu avec les fluids évaporables, et de la formation des fluids élastiques aériformes. (1777d) in Oeuvres de Lavoisier, vol. 2, pp. 212-224. Imprimerie Imperiale, Paris (1862)

Lavoisier, A.-L.: Mémoire sur la combustion en général. (1777e) in Oeuvres de Lavoisier, vol. 2, pp. 212-224. Imprimerie Imperiale, Paris (1862)

Lavoisier, A.-L.: Considérations générales sur la nature des acides et sur les principles dont ils sont composés. (1778) in Oeuvres de Lavoisier, vol. 2, pp. 248-260. Imprimerie Imperiale, Paris (1862) 
Lavoisier, A.-L.: Mémoire dans laquelle on a pour objet de prouver que l'eau n'est point une substance simple, un élément proprement dit, mais qu'elle est susceptible de décomposition et de recomposition, (1783) in Oeuvres de Lavoisier, vol. 2, pp. 334-359. Imprimerie Imperiale, Paris (1862)

Lavoisier, A.-L.: Réflexions sur le Phlogistique, (1785) in Oeuvres de Lavoisier, vol. 2, pp. 623-655. Imprimerie Imperiale, Paris (1862)

Lavoisier, A.-L.: Traité élémentaire de Chimie., Cuchet, Paris (1789); Translated as Elements of Chemistry. Dover, New York (1790)

Lavoisier, A.-L.: Oeuvres de Lavoisier. In: Goupil, M. (ed.) Correspondance, vol. V, pp. 1787-1788. Académie des Sciences, Paris (1993)

Lavoisier, A.-L.: Oeuvres de Lavoisier. In: Bret, P. (ed.) Correspondance vol. VI, pp. 1789-1791. Académie des Sciences, Paris (1997)

Lavoisier, A.-L.: Brisson, Meusnier, Laplace. Extrait des Registres de l'Académie Royale des Sciences, du 28 Août 1790. Annales de Chimie 7, 257-263 (1790)

Lavoisier, A.-L.: Laplace, P. Mémoire sur la Chaleur, (1784) in Oeuvres de Lavoisier, vol. 2, pp. $355-408$. Imprimerie Imperiale, Paris (1862)

Leonhardi, J.: Macquer's Chymisches Wörterbuch, 7 vols. Leipzig (1788-1791)

Macquer, P.: Elements of the Theory and Practice of Chemistry, 2nd edn. Donaldson, Edinburgh (1764)

Macquer, P.: Dictionnaire de Chymie. Paris: Lacombe (1766)

Macquer, P.: Dictionnaire de Chymie, 2nd edn. Barrois, Paris (1778)

Marchand, A.: Über Phlogiston, electrische Materie, Light, Luft, und die unmittelbare Ursache der Bewegung. Mannheim: Schwann und Götz (1787)

Mayow, J.: Tractatus quinque medico-physici... Sheldonian, Oxford (1674); page refs to: trans. A. Brown and L. Dobbin, Medico-Physical Works, Edinburgh: The Alembic Club (1907)

McEvoy, J.: Joseph Priestley, 'Aerial Philosopher': Metaphysics and Methodology in Priestley's Chemical Thought from 1772-1781. Parts 1-3, Ambix 25, 1-55; 93-116, and 153-175; Part 4: Ambix 26, 16-38 (1978-1979)

Morgan, G.: Observations and experiments on the light of bodies in a state of combustion. Philos. Trans. R. Soc. 75, 190-212 (1785)

Morris, R.: Lavoisier and the Caloric theory. Br. J. Hist. Sci. 6, 1-38 (1972)

Murray, J.: A System of Chemistry, 4 vols, 4th edn. Francis Pillans, Edinburgh (1819)

Partington, J.: A History of Chemistry, vol. 3. Macmillan, London (1962)

Priestley, J.: The History and Present State of Electricity with original Experiments, 2nd edn. Dodsley, Johnson, Davenport and Cadell, London (1769)

Priestley, J.: Observations on different kinds of air. Philos. Trans. R. Soc. 62, 147-265 (1772)

Priestley, J.: Experiments and Observations on Different Kinds of Air. Johnson, London (1774)

Priestley, J.: An examination of Dr. Reid's Inquiry into the Human Mind, on the Principles of Common Sense, etc. London: Johnson (1774b). Page refs to Rutt, J. (ed.) The Theological and Miscellaneous Works of Joseph Priestley, vol III. London (1818)

Priestley, J.: Experiments and Observations on Different Kinds of Air, vol. II, Johnson, London (1775a)

Priestley, J.: An account of further discoveries in air; in letters to Sir John Pringle, Bart. P.R.S. and the Rev. Dr. Price, F.R.S. Philos. Trans. R. Soc. 65, 384-394 (1775)

Priestley, J.: Disquisitions Relating to Matter and Spirit. Johnson, London (1777). Page refs to Rutt, J. (ed.) The Theological and Miscellaneous Works of Joseph Priestley, vol III. London (1818)

Priestley, J.: Experiments and Observations Relating to Various Branches of Natural Philosophy, with a Continuation of the Observations on Air, vol. III. Johnson, London (1786)

Priestley, J.: Experiments and observations relating to the principle of acidity, the composition of water and phlogiston. Philos. Trans. R. Soc. 78, 147-157 (1788a)

Priestley, J.: Additional experiments and Observations relating to the principle of acidity, the composition of water and phlogiston. Philos. Trans. R. Soc. 78, 313-330 (1788b)

Priestley, J.: Objections to the experiments and observations relating to the principle of acidity, the composition of water and phlogiston. Philos. Trans. R. Soc. 79, 7-20 (1789)

Priestley, J.: Experiments and Observations on Different Kinds of Air, and Other Branches of Natural Philosophy, Connected to the Subject: Being the Former Six Volumes Abridged and Methodized, with Many Additions, vols. I, II, and III. Johnson, London (1790a-c)

Priestley, J.: Farther Experiments relating to the Decomposition of dephlogisticated and inflammable air. Philos. Trans. R. Soc. 81, 213-222 (1791)

Priestley, J.: Experiments on the Generation of Air from Water. Johnson, London (1793)

Priestley, J.: Heads of Lectures on a Course of Experimental Philosophy Particularly Including Chemistry, Delivered at the New College in Hackney. Johnson, London (1794) 
Rey, J.: Essays de Jean Rey Docteur en Medicine. Sur la Recherche de la cause pour laquelle l'Estain et le Plomb augmentent de poids quant on les calcine. Millanges, Bazas (1630)

Sage, B.-G.: Élémens de Minéralogie Docimastique, 2nd edn. Imprimerie Royale, Paris (1777)

Scheele, C.: The Collected Papers of Carl Wilhelm Scheele. Bell, London (1931)

Séguin, A.: Suite du Mémoire sur la Combustion du Gaz Hydrogène dans des Vaisseaux clos. Ann. Chim. 9, 30-50 (1791)

Stahl, G.: Specimen Beccherianum, sistens fundamenta, documenta, experimenta, quibus principia mixtionis subterraneae \& instrumenta naturalia atque artificialia demonstrantur. Gleditschium, Leipzig (1703)

Stahl, G.: Experimenta, observationes, animadversiones, CCC numero, chymicae et physicae. Haude, Berlin (1731)

Stahl, G.: Traité du Soufre. Didot, Paris (1766)

Stahl, G.: Traité des Sels. Vincent, Paris (1771)

Thomson, T.: A System of Chemistry, 5 vols, 4 edn. Bell and Bradfute, Edinburgh (1810)

Thomson, T.: History of Chemistry. Colburn and Bentley, London (1830)

Westrumb, J.F.: Auch ein Beytrag zu den Theorien vom Feuer, der Luft- und Wassererzeugung. Kleine physikalisch-chemische Abhandlungen 2(1), 1-118 (1787)

Westrumb, J.F.: Kleine physikalisch-chemische Abhandlungen, v. 2, pt. 2. Müller, Leipzig (1788a)

Westrumb, J.F.: Kleine physikalisch-chemische Abhandlungen, v. 3, pt. 1. Müller, Leipzig (1788b)

Westrumb, J.F.: Neue Bemerkungen über einige merkwürdige Erscheinungen durch die dephlogistisirte Salzsäure. Chemische Annalen 1, 3-21; 109-129 (1790)

Westrumb, J.F.: Bemerkungen über die Entzündung mehrerer Körper durch brennstoffleere Salzsäure; vom Hrn Professor Arbogast zu Strasburg. Übersetzt und mit einigen Erläuterungen versehen. Chemische Annalen 1, 10-31; 137-152 (1791)

Wiegleb, J.: Lehrbegriffe vom Phlogiston, auf neue Versuche gegründet. Chemische Annalen 1, 207-229 (1784) 